\title{
Rhizopus Rotting on Agricultural Products in Jakarta
}

\author{
Anastasia Tatik Hartanti" , Amelia Raharjo, Agustin Wydia Gunawan \\ Faculty of Biotechnology, Atma Jaya Catholic University of Indonesia, Jakarta, Indonesia
}

ARTICLE INFO

Article history:

Received July 6, 2018

Received in revised form August 20, 2019

Accepted August 30, 2019

\section{KEYWORDS:}

Rhizopus rot,

ITS rDNA

mold,

postharvest disease,

agriculture

\begin{abstract}
Agricultural products may easily perish if they are not well taken care of during postharvest treatment. One of the main causes in damaged products is the biological contamination of pathogenic fungi, such as Rhizopus spp. that gives rise to Rhizopus rot symptoms. The purpose of this research was to isolate Rhizopus spp. from different agricultural products showing Rhizopus rot symptoms as well as to identify them. Rhizopus pure cultures were isolated on potato dextrose agar. Identification was done through molecular techniques using Phytopure ${ }^{\mathrm{TM}}$ DNA Extraction Kit and Maxwell ${ }^{\circledR}$ RSC Plant DNA Kit for DNA isolation, internal transcribed spacer (ITS4 and ITS5) as primers for amplification, and molecular evolutionary genetics analysis 7 (MEGA7) for the reconstruction of phylogenetic tree from sequence result. The phylogenetic tree using Maximum Likelihood statistics with 1,000 replications of bootstrap test showed five strains, namely AR9, AR10, AR11, AR13, and AR14, which belong to $R$. delemar, and the other seven remaining strains, AR1-AR7 belong to $R$. stolonifer. Identification was clarified with morphological and physiological data using Rhizopus growth at temperature control of 33 and $42^{\circ} \mathrm{C}$ as well as microscopic observation involving rhizoid, columella, measurement of sporangiospores, and sporangiophores.
\end{abstract}

\section{Introduction}

One prevalent cause of crop spoilage is biological contamination. A common group of microorganisms that contaminate agricultural products is Rhizopus spp., a pathogenic fungus that causes decay as well as disease of many fruits and vegetables. Medically, they were known to cause mucormycosis in man and animals. Whereas in agriculture and food, it plays an important role as fermentation and bioremediation agents yielding enzymes that could catalyze the formation of drugs. The beneficial impact of Rhizopus contributes the idea of collecting as many species for further useful applications in the future.

The taxonomy and molecular phylogeny of the genus Rhizopus have been intensively analyzed over several decades. The current classification of Rhizopus is based on revisions published by Schipper (1984), followed by Schipper and Stalpers (1984), who utilized morphological approaches and classified all the species of the genus into the stolonifer-group, $R$. oryzae, and microsporus-group. After this revision, classification based on morphology was further

\footnotetext{
* Corresponding Author

E-mail Address: anast.hartanti@atmajaya.ac.id
}

clarified with accurate phylogenetic relationships. A side from morphological features, Zheng et al. (2007) applied ribosomal RNA-encoding DNA (rDNA) with pyrG sequence analysis for phylogenetic data based on Liu et al. (2007) and re-classified the genus into 10 species and 7 varieties. This was further revised due to obscurities found in the rDNA ITS sequence of $R$. americanus, which had three distinct sequences similar to $R$. stolonifer, $R$. microsporus, and $R$. oryzae. Phylogenetic relationships were re-evaluated using actin gene (act 1$)$, translation elongation factor $1 \alpha$ (EF-1 $\alpha$ ), and rDNA ITS by Abe et al. (2010), who proposed $R$. niveus to be re-classifed as $R$. delemar, $R$. americanus, and $R$. sexualis to be re-classified as $R$. stolonifer. Zheng et al. (2007) replaced $R$. arrhizus to be $R$. oryzae, which differed from Abe et al. (2010), who used the former name.

Morphological identification of Rhizopus as plant pathogen carried out in Indonesia was restricted to genus only. Standard method in every fungal taxonomy requires molecular phylogenetic analysis to reflect morphological features. The purpose of this research was to isolate Rhizopus spp. from varying agricultural products as well as to identify them into species level. 


\section{Materials and Methods}

\subsection{Materials}

Materials used in this research were agricultural products carrying symptoms of Rhizopus rot, including apples (Crab and Fuji), bananas (Cavendish and Latundan), cherry tomato, grapes, guava, peach, pear, strawberry, sweet potato, and tomato obtained from several markets in Jakarta.

\subsection{Methods}

This research consisted of isolation of Rhizopus, molecular identification of Rhizopus, and clarification of Rhizopus species.

\subsection{Rhizopus Isolation}

Rhizopus rot from agricultural products was determined through microscopic clarification of rhizoid structure. Isolation was carried out using direct plating method in potato dextrose agar (PDA) plate containing $250 \mathrm{ppm}$ chloramphenicol. The cultures were incubated at $28^{\circ} \mathrm{C}$.

Suspension of spores from a culture aged 4 days old was conducted to acquire a single hyphae. The single hyphae was transferred to a fresh PDA medium. The single hyphae isolation was incubated at $28^{\circ} \mathrm{C}$ for two days. The single hyphae obtained was transferred to a fresh slanted PDA medium for culture collection.

\subsection{Molecular Identification of Rhizopus}

Rhizopus genomic extraction was done with materials acquired from illustra Nucleon Phytopure ${ }^{\mathrm{TM}}$ Kit. Mycelia were collected from the previous culture collection and transferred to an Eppendorf tube with a $1.5 \mathrm{ml}$ maximum capacity which already contained 500 $\mu \mathrm{lmilliQ}$. Centrifugation at $10,000 \mathrm{rpm}$ for $10 \mathrm{~min}$ was done, followed by removal of supernatant. Pellet was pounded with a plastic pestle until the pellet formed a porridge-like substance. As much as $300 \mu$ of reagent 1 was added, followed by resuspension. As much as 3 $\mu \mathrm{l}$ of RNAse $(20 \mu \mathrm{g} / \mathrm{ml})$ was added, resuspended, then incubated at $37^{\circ} \mathrm{C}$ for $30 \mathrm{~min}$. As much as $200 \mu \mathrm{l}$ of reagent 2 was added and shaken until homogeneous, then incubated at room temperature for $10 \mathrm{~min}$ and put in ice for $20 \mathrm{~min}$. The suspension of mycelia was next added with $500 \mu$ of cold Phenol: Chloroform: Isopropanol, then mixture was shaken for $10 \mathrm{~min}$ at room temperature and centrifuged at $10,000 \mathrm{rpm}$ at $4^{\circ} \mathrm{C}$ for $10 \mathrm{~min}$. The supernatant formed was transferred to a new Eppendorf tube, and then added with cold isopropanol as much as half the tube's volume while homogenizing the mixture slowly. Centrifugation was done at 13,000 rpm for 10 min to get the supernatant which was later removed. As much as $50 \mu \mathrm{l}$ of cold ethanol 70\% was added and centrifuged at 13,000 rpm for $10 \mathrm{~min}$, then supernatant was removed and pellet was air dried for approximately $30 \mathrm{~min}$. As much as $50 \mu \mathrm{l}$ of NFW was added to the pellet, and then kept at $-20^{\circ} \mathrm{C}$. Preparation for ITS4 $\left(5^{\prime}\right.$-TCC TCC GCT TAT TGA TAT GC-3') and ITS5 (5'-GGA AGT AAA AGT CGT AAC AAG G-3') was done to amplify a gene at the site 18S-5.8S-28S using Gene Amp ${ }^{\circledR}$ PCR System 2400 with KAPA Taq EXtra HotStart PCR kit. PCR reactions for each rDNA sample consisted of $1 \mu \mathrm{l}$ of $100 \mathrm{ng}$ DNA sample, $1.5 \mu \mathrm{l}$ of $10 \mathrm{~mm}$ dNTP mix, $3.5 \mu \mathrm{l}$ of $25 \mathrm{~mm}$ $\mathrm{MgCl}_{2}, 2.5 \mu \mathrm{l}$ of $10 \mu \mathrm{m}$ ITS4 and ITS5, $0.5 \mu \mathrm{l}$ of $2.5 \mathrm{U} \mu \mathrm{l}$ Taq polymerase enzyme, $10 \mu$ of $5 X$ KAPA Taq EXtra Buffer, and $28.5 \mu \mathrm{l}$ of NFW. PCR reaction cycle was operated $94^{\circ} \mathrm{C}, 2 \mathrm{~min} ; 35 \mathrm{cycles}$ at $94^{\circ} \mathrm{C}, 15 \mathrm{sec} ; 55^{\circ} \mathrm{C}$, $30 \mathrm{~min} ; 72^{\circ} \mathrm{C}, 1 \mathrm{~min} ; 72^{\circ} \mathrm{C}, 5 \mathrm{~min}$. PCR results were visualized at $1 \%$ agarose gel at $100 \mathrm{~V}$ for $45 \mathrm{~min}$, and then followed by dyeing of ethidium bromide for 15 min. Gel was rinsed with aquades and observed using UV light (Hartanti et al. 2015).

Isolates unsuccesfully extracted and amplified with Phytopure $^{\mathrm{TM}}$ DNA Extraction Kit were treated with a quick protocol from Promega Maxwell ${ }^{\circledR}$ RSC Plant DNA Kit with the Maxwell ${ }^{\circledR}$ RSC System (AS4500). As much as $20 \mathrm{mg}$ sample was placed at the bottom of a ClickFit microtube with a $1.5 \mathrm{ml}$ capacity. Liquid nitrogen was added to the sample to freeze the sample. Using a plastic pestle, the frozen sample was grinded against the tube wall. As much as $300 \mu$ l tail lysis buffer (TLA) was added to each tube, then followed by $10 \mu \mathrm{l}$ RNAse. All tubes were vortexed briefly for $10 \mathrm{sec}$. and centrifuged at $13,000 \mathrm{rpm}$ for $2 \mathrm{~min}$. A deck tray and cartridges from the kit were set up. An amount of $300 \mu \mathrm{l}$ of NFW was added to the first well of each Maxwell ${ }^{\circledR}$ RSC Plant DNA Kit reagent cartridge. The sample lysate, excluding any solid materials, was transferred from the extraction tube to the first well of the reagent cartridge. Samples were then programmed under Maxwell ${ }^{\circledR}$ RSC System into automated purification with $45 \mathrm{~min}$. duration.

The results of PCR were sequenced by 1st Base, Malaysia. DNA sequence was edited using ChromasPro2. Edited sequence was aligned with DNA database reference in Gene Bank, including Rhizopus type species (www.ncbi.nih.gov/Genbank), using MEGA7 with outgroup Phycomyces blakesleeanus. Alignment result was used to construct the phylogenetic tree using MEGA7 with maximum likelihood (ML) method. 


\subsection{Clarification of Rhizopus Species}

Morphological observation was made through Riddle's slide culture technique. Microscopic examination involved the measurement of sporangiophore's length and sporangiospore's diameter, as well as the sight of rhizoid and columella. Physiological observation utilized five PDA plates inoculated from each strain which were incubated at 33 and $42^{\circ} \mathrm{C}$ for two days.

\section{Results}

Twelve Rhizopus strains were succesfully isolated from nine types of agricultural products (Table 1 ). Diversities of Rhizopus spp. in agricultural products were classified based on rDNA-ITS region tree generated from ML analysis which identified $R$. delemar (5 strains) and $R$. stolonifer (7 strains) with 1,000 bootstrap replications and Tamura-Nei model (Figure 1).

\subsection{Maximum Temperature and Morphology of Rhizopus}

Molecular data was clarified with physiological data. Strains AR1-AR7 showed no growth at $33^{\circ} \mathrm{C}$, while strains AR9-AR11, AR13, and AR14 showed growth at $33^{\circ} \mathrm{C}$, and no growth at $42^{\circ} \mathrm{C}$ (Table 2).

Rhizopus delemar strains were identified through microscope having sporangiophores measuring between 120.43-1088.5 $\mu \mathrm{m}$ with swellings commonly observed. Sporangiophores were seen usually in one cluster arising from rhizoid. Rhizoid was not well developed, not abundant, and appeared to resemble a finger. Its columella showed distinct apophyses. Sporangiospores

Table 1. Sample origin, strain code, location and date of isolation, and accession number acquired

\begin{tabular}{|c|c|c|c|c|}
\hline $\begin{array}{l}\text { Sample } \\
\text { origin }\end{array}$ & $\begin{array}{l}\text { Strain } \\
\text { code }\end{array}$ & $\begin{array}{l}\text { Location of } \\
\text { isolation }\end{array}$ & Species & $\begin{array}{l}\text { Accession } \\
\text { number }\end{array}$ \\
\hline Apple (Crab) & AR5 & Jakarta & R. stolonifer & MF461024 \\
\hline Apple (Fuji) & AR11 & Jakarta & R. delemar & MF445158 \\
\hline $\begin{array}{l}\text { Banana } \\
\text { (Cavendish) }\end{array}$ & AR4 & Jakarta & R. stolonifer & MF461023 \\
\hline $\begin{array}{l}\text { Banana } \\
\text { (Latundan) }\end{array}$ & AR1 & Jakarta & R. stolonifer & 1020 \\
\hline $\begin{array}{l}\text { Cherry } \\
\text { tomato }\end{array}$ & AR14 & Jakarta & R. delemar & MF445161 \\
\hline Grape & AR2 & Jakarta & R. stolonifer & MF461021 \\
\hline Guava & AR6 & Jakarta & R. stolonifer & MF461025 \\
\hline Peach & AR13 & Jakarta & R. delemar & MF445160 \\
\hline Pear & AR7 & Jakarta & R. stolonifer & MF461026 \\
\hline Strawberry & AR3 & Jakarta & R. stolonifer & MF461022 \\
\hline potato & AR9 & Jakarta & R. delemar & MF445156 \\
\hline Tomato & AR10 & Jakarta & R. delemar & MF445157 \\
\hline
\end{tabular}

were variable in shapes and sizes measuring between 2.31-10.23 $\mu \mathrm{m}$ (Figure 2). In macroscopic examination, all $R$. delemar strains showed colonies that were white initially, then becoming grey to black at the entire upper portion, showing a maturing process.

Rhizopus stolonifer strains were identified through microscope having well developed and abundant rhizoid repeatedly branching. Sporangiospores were irregular and measuring between 5.41-24.55 $\mu \mathrm{m}$, while sporangiophores between 463.69-2683.87 $\mu \mathrm{m}$. Its columella showed distinct apophyses (Figure 3 ). In macroscopic examination, all strains had their colonies white at the central portion and black at the outer edge.

\section{Discussion}

Twelve strains were identified until species level using molecular technique with supporting morphological and physiological data. According to phylogenetic analysis, strains AR9-11 and 13-14 were in concordance with type species $R$. delemar CBS120 12T AB181318. The monophyletic clades of $R$. delemar and $R$. oryzae were further separated at $99 \%$ bootstrap value, which made both species be in different clades. Strains AR1-AR7 were confirmed as R. stolonifer within its subclades that weren't in the clade with the two types of species $R$. americanus CBS340 62T AB113010 and $R$. sexualis CBS336 39T AB113020. This occurence is interesting to be studied further for taxonomic studies, using multigene approach in order to validate the identification of these strains.

The maximum temperatures of $R$. delemar and $R$. stolonifer were evaluated. $R$. delemar strains showed no growth at $42^{\circ} \mathrm{C}$, but survived at $33^{\circ} \mathrm{C}$. This is similar to Zheng et al. (2007), who stated that $R$. arrhizus var. delemar had a maximum temperature reaching $42^{\circ} \mathrm{C}$. $R$. arrhizus var. delemar current name is $R$. delemar. $R$. oryzae had the same maximum temperature with $R$. delemar. $R$. stolonifer strains showed no growth at $33^{\circ} \mathrm{C}$, which is also similar to Zheng et al. (2007), who stated that $R$. stolonifer had a maximum temperature not exceeding $33^{\circ} \mathrm{C}$. The maximum temperature of every strain recorded adhered well with the molecular data.

Morphology results were compared to Zheng et al. (2007) as part of identifying strains AR1-AR14. All strains showed coherence with the reference. Colonies of $R$. delemar and $R$. stolonifer on PDA were found to be deep gray to nearly black. Development of rhizoids are well developed on $R$. stolonifer but less well developed on R. delemar. Rhizopus delemar had sporangiophores 


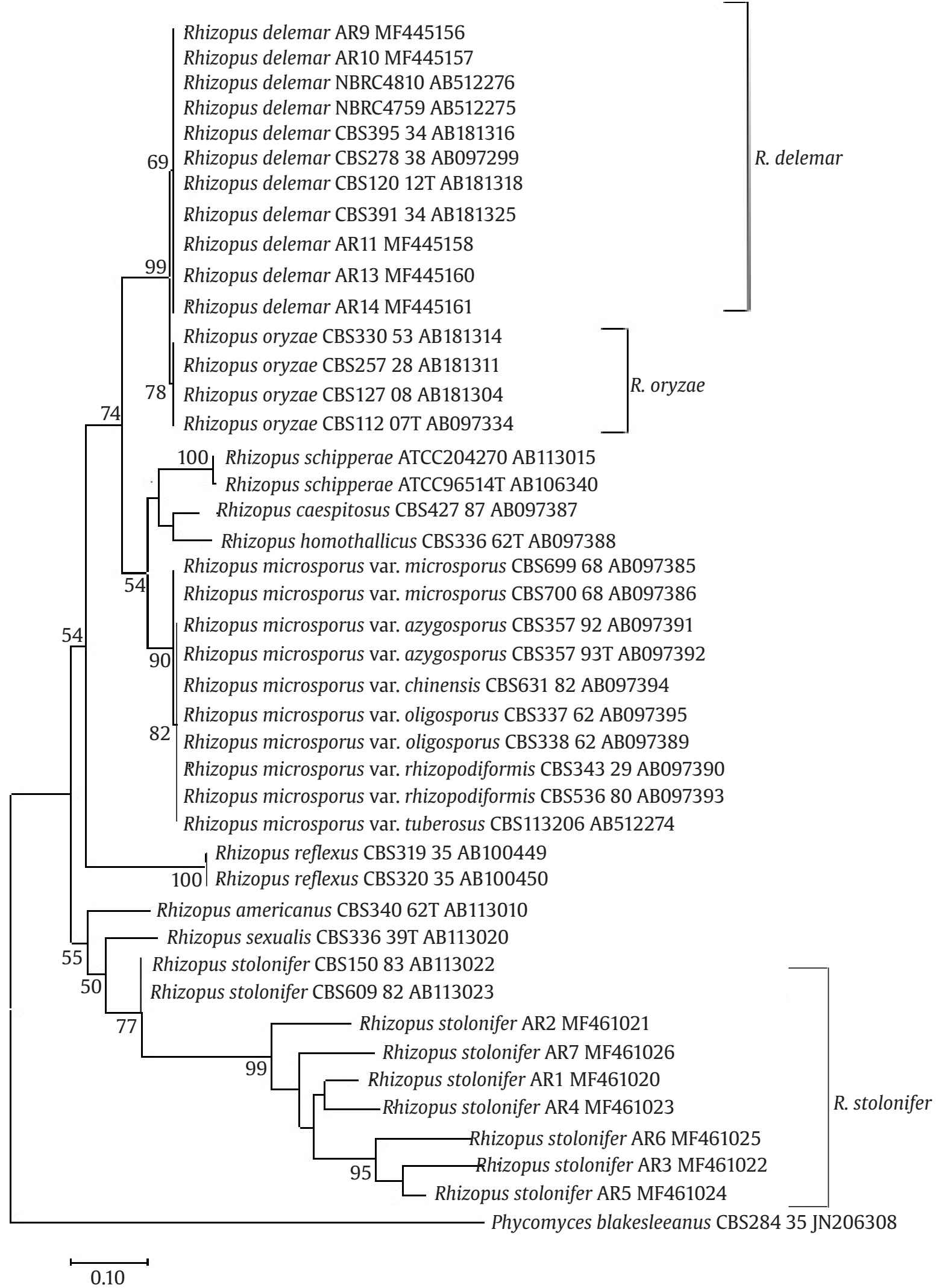

Figure 1. Phylogenetic tree of Rhizopus strains AR1-7, 9-11, 13-14 compared to the reference species using Maximum Likelihood statistics with 1,000 replications of bootstrap test 
Table 2. Physiological data of Rhizopus delemar and Rhizopus stolonifer conducted at temperature growth 33 and $42^{\circ} \mathrm{C}$

\begin{tabular}{lcc}
\hline Strain code & $33^{\circ} \mathrm{C}$ & $42^{\circ} \mathrm{C}$ \\
\hline R. stolonifer AR1 & - & \\
R. stolonifer AR2 & - & \\
R. stolonifer AR3 & - & \\
R. stolonifer AR4 & - & \\
R. stolonifer AR5 & - & \\
R. stolonifer AR6 & - & \\
R. stolonifer AR7 & - & - \\
R. delemar AR9 & + & - \\
R. delemar AR10 & + & - \\
R. delemar AR11 & + & - \\
R. delemar AR13 & + & - \\
R. delemar AR14 & + & \\
\hline
\end{tabular}

R. delemar AR14

Annotation: (+) growth, (-) no growth
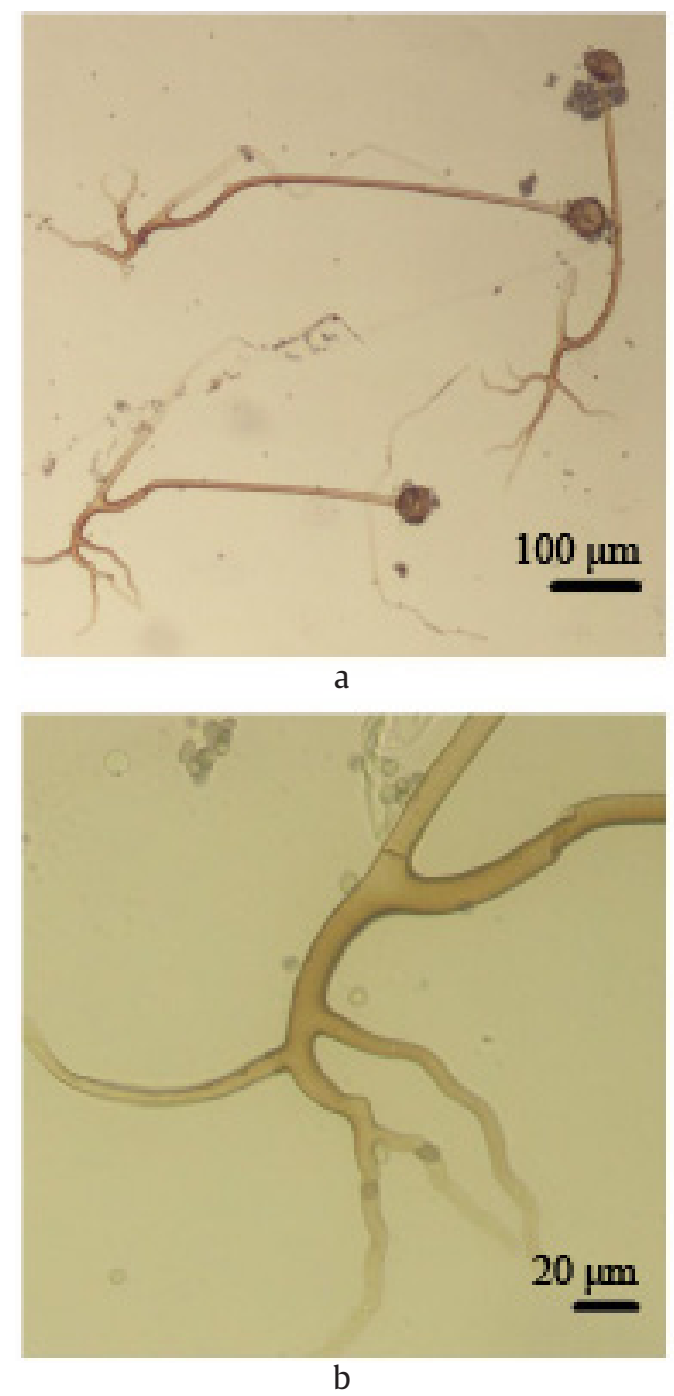

measuring mostly within $1,000 \mu \mathrm{m}$, and reaching 1,700 $\mu \mathrm{m}$ or more in length; in this study $120.43-1,088.50 \mu \mathrm{m}$ of sporangiophore's length was acquired. $R$. stolonifer had sporangiophores measuring mostly within 2,500 $\mu \mathrm{m}$, reaching $3,000 \mu \mathrm{m}$ or more in length; in this study 463.69-2,683.87 $\mu \mathrm{m}$ of sporangiophore's length was acquired. Swellings were supposedly seen mostly at the apex or the middle portion of the $R$. delemar sporangiophores; meanwhile, $R$. stolonifer had no swellings present. Both $R$. delemar and $R$. stolonifer are typically ovoid, ellipsoidal, or roundish conical shaped columellae. The diameter of sporangiospores on $R$. delemar is mostly $5-9(-14.5) \mu \mathrm{m}$, and when irregular it reached $53 \mu \mathrm{m}$ in length; in this study 2.31 -

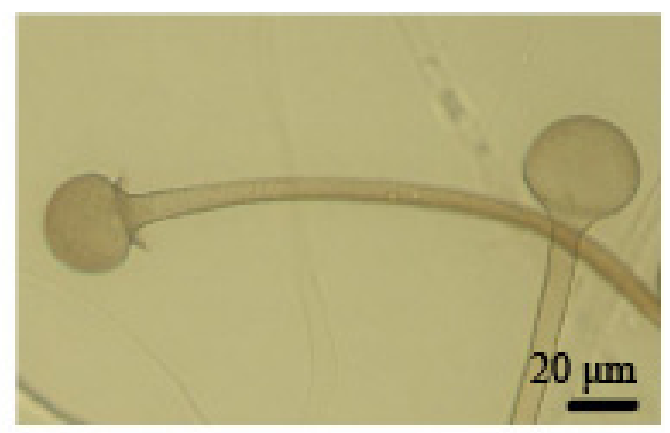

C

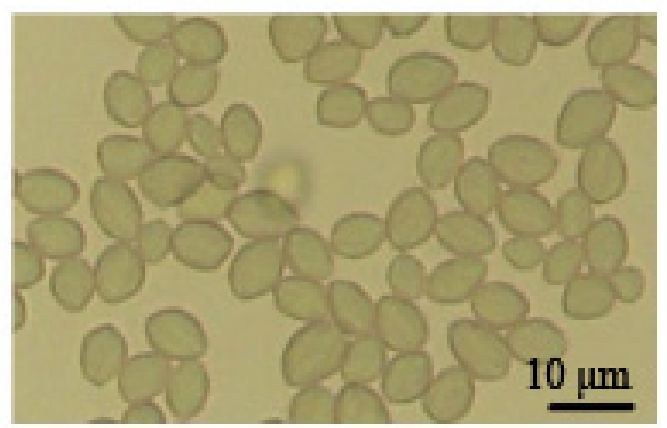

d

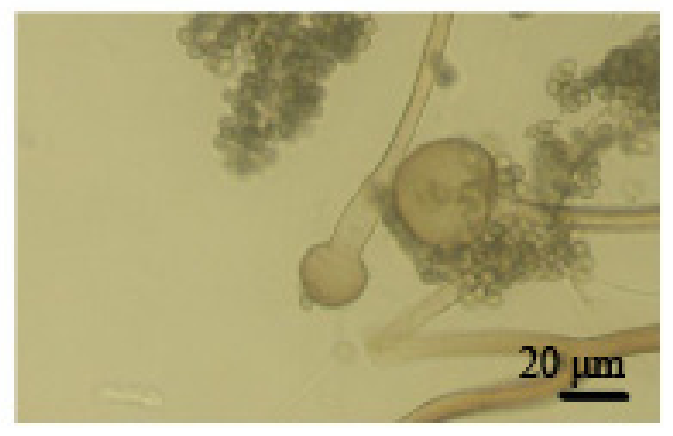

e

Figure 2. Rhizopus delemar strain collected from cherry tomato and peach: (a) sporangiophores in one cluster arising from rhizoid, (b) finger-like shaped rhizoid, (c) columella with distinct apophyses, (d) irregular shaped sporangiospores, (e) swelling on sporangiophore 


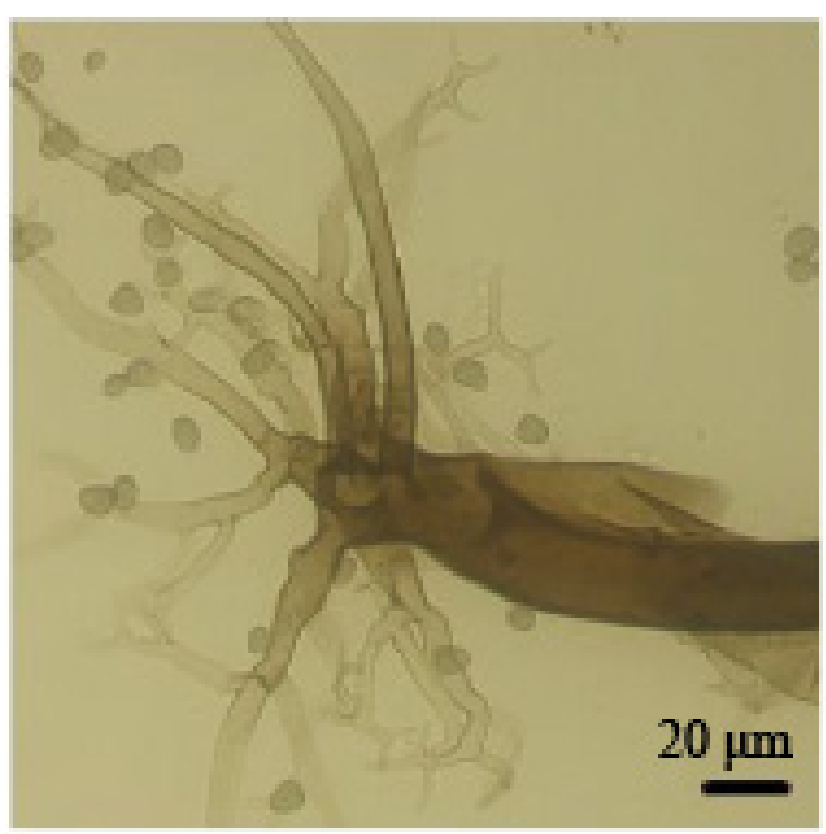

a

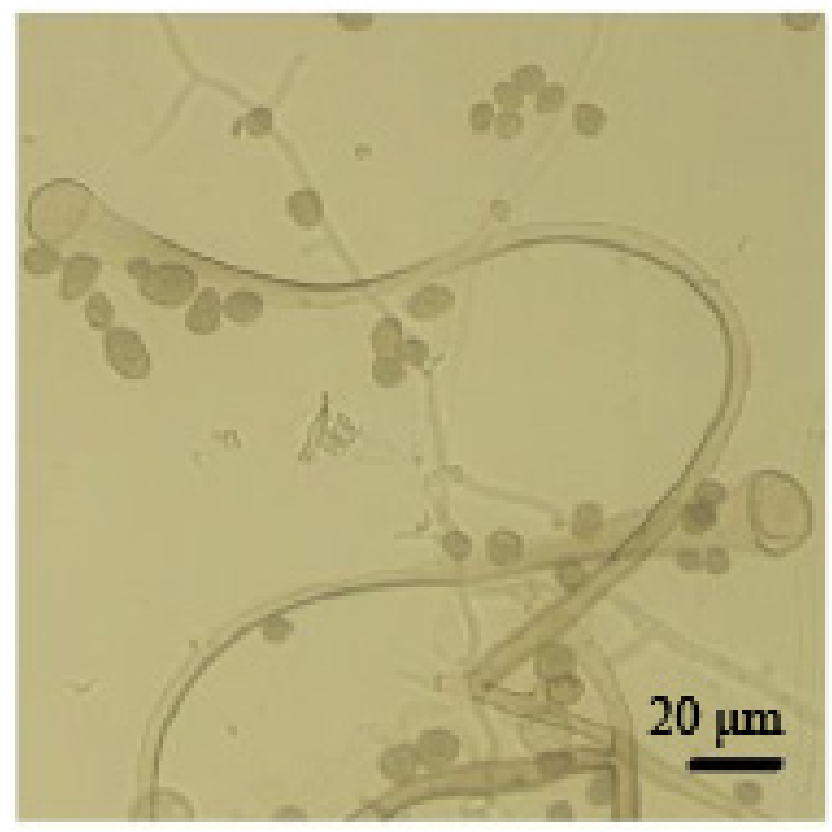

C

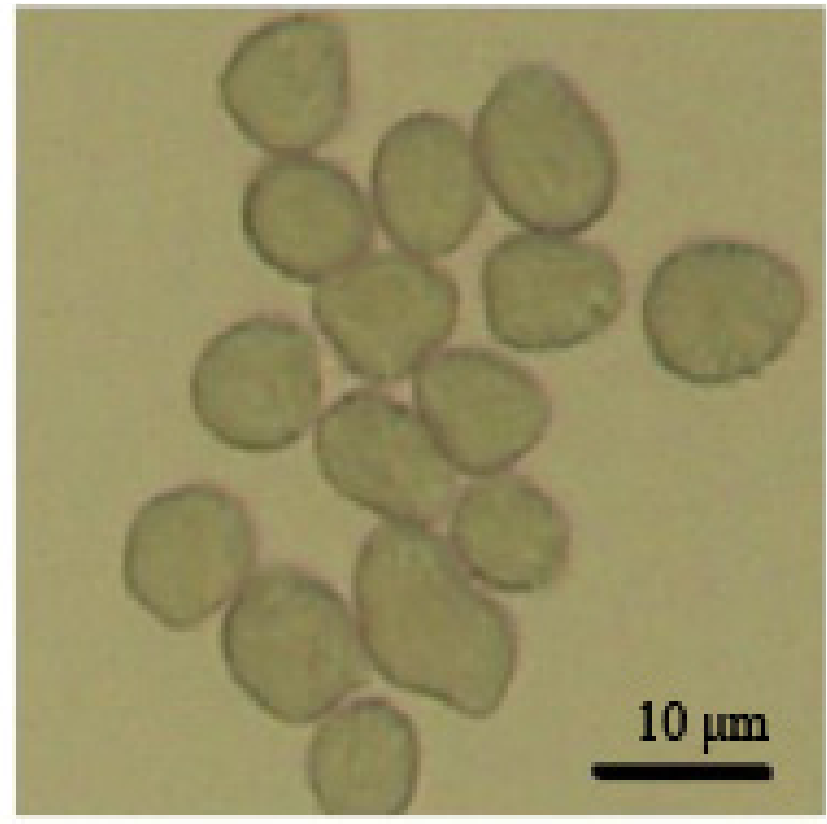

b

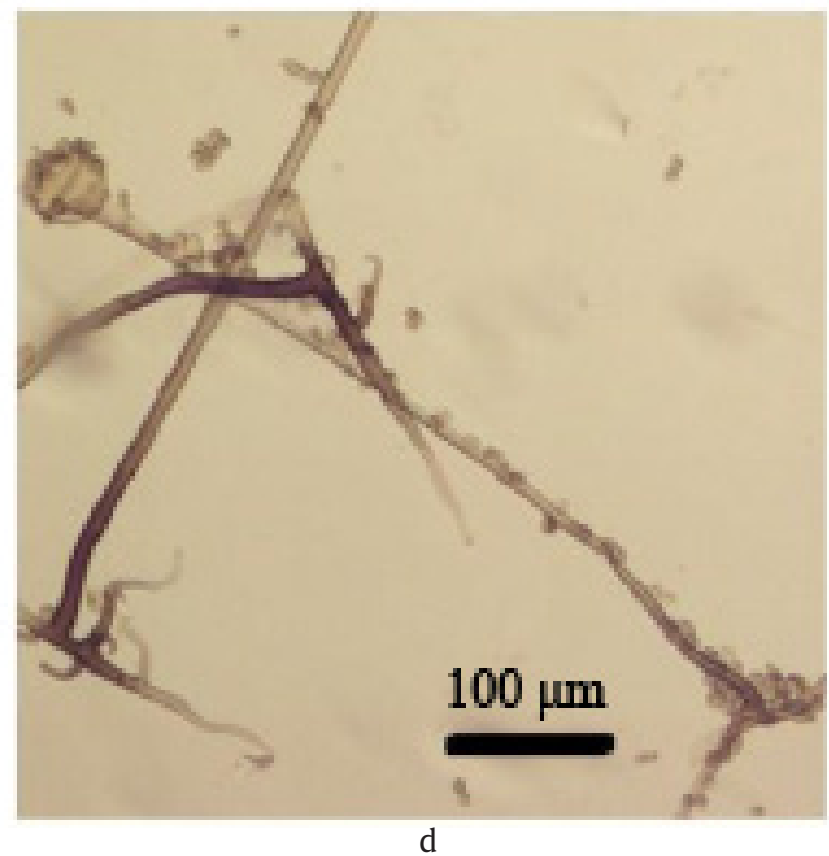

Figure 3. Rhizopus stolonifer strain colleted from apple, banana, and pear: (a) profusely branched rhizoid, (b) irregular shaped sporangiospores, (c) columellae with distinct apophyses, (d) sporangiophores in single clusters arising from rhizoid

$10.23 \mu \mathrm{m}$ of sporangiospore's diameter was acquired. Rhizopus stolonifer had sporangiospores with a diameter measuring mostly 5-12.5 (-19) $\mu \mathrm{m}$; in this study 5.41$24.55 \mu \mathrm{m}$ of sporangiospore's diameter was acquired.

Rhizopus spp. can be divided into fumaric-malic acid producers, lactic acid producers, and producers of both. Although there wasn't a clear correlation between organic producers and morphological classification, $R$. delemar and $R$. oryzae were distinct from each other by the acids they produced. Rhizopus delemar was reported to be lacking ldhA gene, which was responsible in the production of lactic acid; furthermore, $R$. delemar was classified to be a fumaric-malic acid producer. On the other hand, $R$. oryzae was capable of producing lactic acid, thus making $R$. oryzae different from $R$. delemar (Abe et al. 2007). 
Abe et al. (2010) reported that $R$. americanus, $R$. sexualis, and $R$. stolonifer shared morphological and physiological features. However, $R$. stolonifer is heterothallic, and both $R$. americanus and $R$. sexualis are homothallic, so these strains are classified as independent species in morphological taxonomy. A molecular phylogeny cluster occuring in phylogenetic trees based on rDNA-ITS, act1, and EF- $1 \alpha$ consisted of $R$. reflexus, $R$. stolonifer, $R$. sexualis, and $R$. americanus. Abe et al. (2010) reclassified these species to be in the $R$. stolonifer group. However, high divergence and multiple types sequences in this cluster should be modified further for conclusive taxonomy.

Rhizopus stolonifer AR7, AR6, and AR2 is similar to $R$. stolonifer occuring on pear (Kwon and Lee 2006), guava (Ooka 1980) and grapes (Latorre et al. 2002). Although R. delemar AR10 and AR14 were found on cherry tomato and tomato, $R$. stolonifer has been reported to be the fruit pathogen as well (Kwon et al. 2001). Rhizopus stolonifer AR1, AR3, AR4, AR5 and R. delemar AR11, AR9 contradict reports of $R$. oryzae invading banana, apple, sweet potato, and strawberry (Kwon et al. 2011, 2012a, 2012b, 2014). Although R. delemar AR13 occured on peach, this product had the potential in experiencing $R$. stolonifer rot (Kwon and Lee 2006). Host nutrients and acidic $\mathrm{pH}$ are required for all Rhizopus species to germinate optimally, thus different agricultural products from different origins do not trigger species specific growth. There's no clear correlation between the host nutrients, in this case agricultural products, and Rhizopus species. However, environmental factor affects prominently in the infection of species specific pathogens, which might result in inconsistencies of Rhizopus spp. discoveries from different regions. The ecology and distribution of Rhizopus spp. on fruits or vegetables are inadequate in mild or tropical regions; therefore, it is hard to conclude whether some of the known fungi are limited to specific hosts and geography.

Rhizopus spp. are capable of producing significant amount of organic acids and enzymes that could be used in industries and medicinal uses. Rhizopus delemar and $R$. stolonifer produce fumaric acid used in plastic industry, and to a lesser extent, in the food industry (Roa Engel et al. 2008). Rhizopus stolonifer also produces lactic acid and is often used in dairy industry as preservatives or flavour enhancer (Soccol et al. 1994). Rhizopus stolonifer was reported to bring about hydroxylation in the synthesis of steroid used in treating hormonally imbalanced individuals, patients with auto-immune diseases, and as birth control pills (Nassiri-Koopaei and Faramarzi 2015). Rhizopus delemar was reported to produce extracellular lipase capable of acidolysis. The lipase acted strong on myristic, palmitic, palmitoleic, stearic, oleic, linoleic, and $\alpha$-linolenic acids, hence, making it useful in oil companies or biodiesel production (Shimada et al. 1997). Protease produced by $R$. stolonifer is of greater importance due to its higher protease producing activity. Protease is essential in about $60 \%$ of total enzyme market and capable of digesting insoluble materials such as cellulose and protein (Kranthi et al. 2012). Naming and validating a specific Rhizopus species is an essential step to ensure the role and benefit of the actual sample acquired.

\section{Conclusion}

Twelve strains were successfully isolated and identified from nine different types of agricultural products. Five strains were identified as $R$. delemar and the other seven remaining strains were identified as $R$. stolonifer. These strains have the potential to yield useful organic acids and enzymes for many types of industries.

\section{Acknowledgements}

The authors would like to thank Faculty of Biotechnology, Atma Jaya Catholic University of Indonesia for providing a fund to support this research.

\section{References}

Abe A et al. 2007. Rhizopus delemar is the proper name for Rhizopus oryzae fumaric-malic acid producers. Mycologia 99:714-722.

Abe A et al. 2010. A molecular phylogeny-based taxonomy of the genus Rhizopus. Biosci Biotechnol Biochem 74: 1325-1331.

Hartanti AT et al. 2015. Rhizopus species from fresh tempeh collected from several regions in Indonesia. HAYATI J Biosci 22:136-142.

Kranthi VS et al. 2012. Protease production by Rhizopus stolonifer through solid state fermentation. Cent Eur J Biol 1:113-117.

Kwon JH et al. 2001. Rhizopus soft rot on cherry tomato caused by Rhizopus stolonifer in Korea. Mycobiology 29:176-178.

Kwon JH, Lee CJ. 2006. Rhizopus soft rot on pear (Pyrus serotina) caused by Rhizopus stolonifer in Korea. Mycobiology 34:151-153.

Kwon JH et al. 2011. First report of Rhizopus oryzae as a postharvest pathogen of apple in Korea. Mycobiology 39:140-142.

Kwon JH et al. 2012a. First report of Rhizopus oryzae as a postharvest pathogen of sweet potato in Korea. Plant Pathol J 28:114.

Kwon JH et al. 2012b. Soft rot of Rhizopus oryzae as a postharvest pathogen of banana fruit in korea. Mycobiology 40:214216.

Kwon JH et al. 2014. Rhizopus fruit rot caused by Rhizopus oryzae on strawberry. J Agric Life Sci 48:27-34. 
Latorre BA et al. 2002. Severe outbreaks of bunch rots caused by Rhizopus stolonifer and Aspergillus niger on table grapes in Chile. APS 86:815.

Liu XY et al. 2007. Molecular phylogenetic relationships within Rhizopus based on combined analyses of ITS rDNA and pyrG gene sequences. Sydowia 59:235-253.

Nassiri-Koopaei N, Faramarzi MA. 2015. Recent developments in the fungal transformation of steroids. Biocatal Biotransformation 33:1-28.

Ooka JJ. 1980. Guava fruit rot caused by Rhizopus stolonifer in Hawaii. Plant Dis 64:412-413.

Roa Engel CA et al. 2008. Fumaric acid production by fermentation. Appl Microbiol Biotechnol 78:379-389.
Schipper MAA. 1984. A revision of the genus Rhizopus. I. The Rhizopus stolonifer group and Rhizopus oryzae. Stud Mycol 25:1-19.

Schipper MAA, Stalpers JA. 1984. A revision of the genus Rhizopus. II. The Rhizopus microsporus group. Stud Mycol 25:30-34.

Shimada Y et al. 1997. Fatty acid specificity of Rhizopus delemar lipase in acidolysis. J Biosci Bioeng 83:321-327.

Soccol CR et al. 1994. Production of L-lactic acid by Rhizopus species. World J Microbiol Biotechnol 10:433-435.

Zheng RY et al. 2007. A monograph of Rhizopus. Sydowia 59:273-372. 